\title{
Dimensões básicas da religiosidade belo-horizontina
}

\author{
ALEXANDRE CARDOSO
}

\section{O módulo de religião} da pesquisa da Região Metropolitana de Belo Horizonte

$\mathrm{O}$ S DADOs que exploramos a seguir foram produzidos por um survey da Região Metropolitana de Belo Horizonte, iniciado em 2001 e finalizado em 2002, parte de um projeto maior, denominado Social Hubble, que prevê a realização de surveys semelhantes e bienais em Pequim, Varsóvia, Cidade do Cabo e Detroit a partir de 2004. Com uma amostra probabilística de 1.029 casos, o de Belo Horizonte, que teve a função de projeto-piloto, foi concebido por oito grupos de professores e pesquisadores da UFMG e de outros centros de pesquisa, a maioria do Departamento de Sociologia e Antropologia e do Departamento de Ciência Política. Cada grupo se encarregou de um módulo temático do questionário, sendo o de religião o objeto principal de nossas considerações. Além dele, utilizamos os módulos básico, de raça e de estratificação para alguns cruzamentos.

O desenho do módulo de religião foi concebido de modo que, com um número pequeno de questões, produzisse não apenas dados sobre o pertencimento religioso das pessoas, mas também sobre seus envolvimentos institucionais com as igrejas e mágicos "profissionais”, bem como sobre o universo de crenças mágico-religiosas e até mesmo de poderes mágicos que admitem ter. A primeira pergunta, sobre crenças, indagava diretamente ao entrevistado se ele acreditava em uma série de coisas, definidas de acordo com referências da sociologia da religião no Brasil ${ }^{1}$. A segunda indagava se ele participava de uma série de atividades religiosas. A terceira, se ele acreditava possuir um conjunto de dons, que também lhe eram apresentados, e só então perguntávamos a qual religião pertencia, e também, nesse caso, apresentávamos opções.

Essa ordem de questões, bem como as dos itens enunciados em cada uma delas, foi concebida a partir da suposição, amplamente apontada em estudos qualitativos, de uma forte marca sincrética na religiosidade brasileira ${ }^{2}$. Queríamos, desse modo, dar oportunidade aos entrevistados de indicar suas idéias e ações mágico-religiosas, mais do que cobrar-lhes uma definição, lembrando-lhes de possibilidades que pudessem permanecer ocultas a uma abordagem direta e convencional. Como se verá, tal estratégia produziu um conjunto de dados que, se de um lado, se conformam às suposições teóricas da pesquisa, de outro, reve- 
lam dimensões um tanto inusitadas e instigadoras, do ponto de vista de seu significado cultural, da vida religiosa dos belo-horizontinos. As freqüências simples e alguns cruzamentos já fornecem material para hipóteses interessantes, que não serão tratadas ou testadas, senão apenas aventadas aqui. Os dados permitem também que se pensem relações entre religião e outras dimensões da vida social, também medidas na pesquisa, aqui apenas sugeridas através de três cruzamentos.

\section{Um mosaico de crenças}

O conjunto de “coisas” enunciadas aos entrevistados, sobre as quais eles deveriam manifestar sua crença ou não, procurou reproduzir aproximativamente as referências mais recorrentes, algo como matrizes das crenças mágico-religiosas brasileiras, que se revelam nos estudos do campo. Pode-se concebê-las também como tipicamente relacionadas a determinados "estilos" de religiosidade. Assim, a noção amplamente disseminada de uma divindade monoteísta relacionada à tradição judaico-cristã foi subsumida na palavra "Deus" apresentada aos entrevistados. Do mesmo modo, cada um dos outros nove itens de crença seria integrante típico de um estilo de religiosidade e o seu conjunto representaria o espectro de crenças mais comuns detectadas pelas pesquisas (qualitativas, principalmente) do campo religioso brasileiro e adaptado ao conhecimento específico sobre Belo Horizonte. A ordem dos itens foi apresentada na forma em que aparece na tabela abaixo, tanto nesse caso, como na ordem das questões, visando a evitar que os entrevistados produzissem alguma compatibilização ad hoc de suas crenças e, decorrente de resultados pré-teste, incluímos as opções de resposta "em termos/ mais ou menos".

Grosso modo, os itens "Deus", "Bíblia" e "Demônio (poder do mal)" remetem ao núcleo de crenças cristãs e poderiam ser chamadas "cristãs fundamentais". Do total de crenças admitidas, $41,3 \%$ se referem a esses itens. Os itens "Nossa Senhora", "Santos" e "Poder das orações" completariam o cosmo cristão em seus aspectos mais "democráticos”, no sentido das concessões doutrinárias do catolicismo sacerdotal às demandas de eficácia mágica das massas ${ }^{3}$. Tais crenças poderiam ser chamadas de "cristãs populares" e perfazem $38 \%$ do total das crenças admitidas.

Os itens "Espírito" e "Feitiço" se referem tipicamente ao cosmo adjacente à religiosidade dominante, representado principalmente pelas religiões "mediúnicas", que incluiriam desde as formas mais "africanizadas" do culto dos orixás, até as formas mais "cristianizadas" do espiritismo, conforme a famosa formulação de Camargo (1973). Essas crenças perfazem 13,2\% do total de crenças admitidas.

Os dois outros itens, "Horóscopo" e "Seres extraterrestres" representariam tipicamente a parte restante do universo mágico-religioso creditado à população, constituído de uma miríade de formas menores, no sentido organizacional. Esse conjunto representa $7,5 \%$ do total das crenças admitidas. 
Somando-se todas as respostas afirmativas sobre crenças, incluindo-se "em termos / mais ou menos", chega-se a uma média de 6,1 crenças / pessoa na amostra. Embora não se disponha de dados similares para comparações, pode-se supor que esse número seja significativamente grande, implicando um estilo de religiosidade caracteristicamente sincrética prevalecente na população belohorizontina.

O quadro em barras resulta em um perfil "alto" de crenças, que pode estar a indicar claramente a dimensão sincrética, não fundamentalista, da religiosidade belo-horizontina, pois ao lado das crenças "fundamentais" encontramos valores altos das crenças "democráticas" e, em menor vulto, mas ainda significativamente, as crenças "mediúnicas" e as "esotéricas".

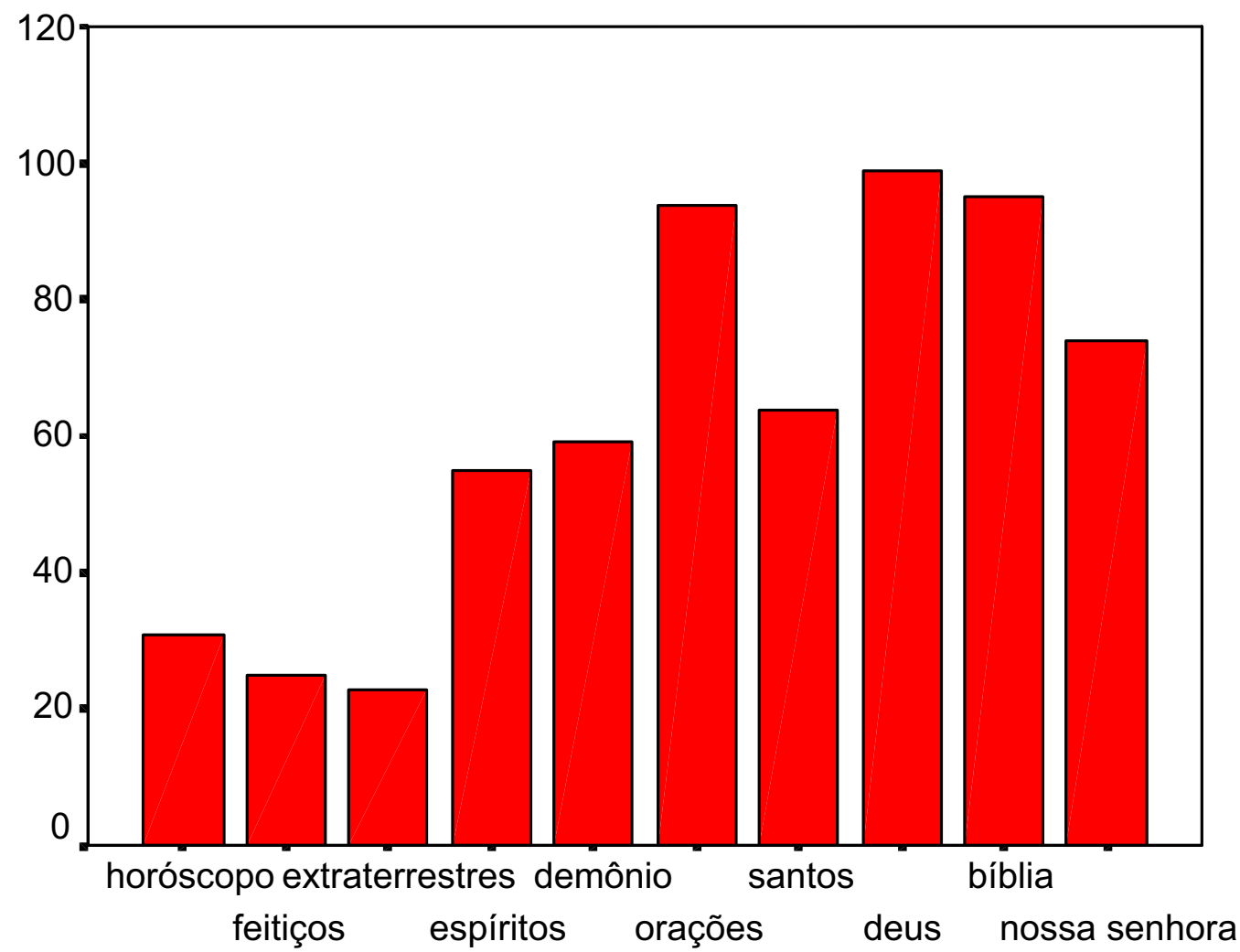

Pode-se tomar o predomínio de crenças "fundamentais" e "democráticas" cristãs e discuti-lo relativamente a muito alardeada diversidade religiosa brasileira, ou seja, a idéia corrente que aponta para uma grande diversidade de crenças e práticas religiosas assimiladas de outras culturas e tradições religiosas, como aspecto marcante de nossa religiosidade e, por extensão, da contemporaneidade. Diríamos, pelos nossos dados, que a diversidade é relativa e amplamente dominada pelas tradições cristãs. Com efeito, concedendo-se que a crença em espíritos 
pode ser integrada ao cosmo cristão, esse perfaz 80,1 \% das crenças admitidas na amostra.

Além do aspecto alto do perfil de crenças, expresso nos altos escores de todas as crenças e particularmente nas cristãs, observa-se neste perfil uma distribuição em que as "democráticas" rivalizam em proporção com as "fundamentais", indicando mais uma vez um estilo de religiosidade "não fundamentalista". Esta característica negativamente expressa certamente é da maior relevância em seu significado cultural, face aos atuais conflitos em diversas regiões da Terra envolvendo estilos de religiosidade fundamentalistas.

\section{Um trânsito intenso}

As cinco questões seguintes do módulo procuraram medir o envolvimento e o trânsito das pessoas pelas várias instituições mágico-religiosas. Assim, foram perguntadas sobre sua participação em "missa”, "culto evangélico”, “promessa religiosa", "reunião espírita" e "consulta a astrólogo, cartomante, mãe/pai de santo ou algum tipo de vidente". Como na primeira questão, esses itens foram escolhidos na suposição de poderem representar tipicamente as ações dos principais grupos religiosos, que nossas hipóteses teóricas nos apontavam: católicos "fundamentais", "populares", evangélicos, espíritas e os da "magia"4. Foram usados filtros nessas questões de modo a captar dimensões do trânsito religioso das pessoas para além de suas confissões religiosas ou daquilo que poderíamos chamar de "conversão clássica". Assim, depois de perguntar se iam à missa, perguntamos aos que responderam não, se já foram, se poderiam ir ou se nunca iriam. Fizemos o mesmo com a questão relativa ao culto evangélico, à promessa religiosa, à reunião espírita e à consulta a astrólogo, cartomante, mãe/pai de santo ou algum tipo de vidente. Os resultados obtidos são também sugestivos, conforme mostram as tabelas abaixo:

Freqüência à missa

\begin{tabular}{c|c|c}
\hline Categoria & Contagem de respostas & Percentual de respostas \\
\hline Sim & 1008 & 52.0 \\
\hline Não & 929 & 48.0 \\
\hline Total & 1937 & 100.0 \\
\hline
\end{tabular}

Somando-se as respostas positivas (se vai, se já foi ou se poderia ir) chegamos a um total de $52 \%$ de indivíduos da amostra que assistem, assistiram ou estão dispostos a assistir a uma missa. Esse dado parece-nos expressivamente pequeno em relação à imagem largamente difundida de um "país católico". Ainda mais em Belo Horizonte, que pelo Censo, é a mais católica das capitais brasileiras.

Em relação à freqüência a culto evangélico, tem-se que 39\% dos respondentes freqüentam, freqüentaram ou estão dispostos a freqüentá-los. Aqui, ao contrário, temos uma imagem bem mais ampliada que a habitual do cosmo evangélico. 
Freqüência a culto evangélico

\begin{tabular}{c|c|c}
\hline Categoria & Contagem de respostas & Percentual de respostas \\
\hline Sim & 927 & 39,0 \\
\hline Não & 1452 & 61,0 \\
\hline Total & 2378 & 100.0 \\
\hline
\end{tabular}

Já sobre o cumprimento de promessas religiosas, tem-se que 30,5\% dos respondentes cumprem, já cumpriram ou estão dispostos a cumpri-las, ou seja, essa é, talvez, a forma de ação tipicamente religiosa, no sentido mais tradicional possível, de sua vinculação pessoal, pouco ou nada institucional, com a crença, mais disseminada que se pode encontrar entre nós.

Freqüiência sobre cumprimento de promessa religiosa

\begin{tabular}{c|c|c}
\hline Categoria & Contagem de respostas & Percentual de respostas \\
\hline Sim & 856 & 30,5 \\
\hline Não & 1953 & 69,5 \\
\hline Total & 2809 & 100.0 \\
\hline
\end{tabular}

Sobre a participação em reuniões espíritas, tem-se que 18,8\% dos respondentes participam, participaram ou estão dispostos a participar delas. Esse dado consegue, talvez, mostrar de um modo bastante persuasivo as reais dimensões do cosmo espírita, sempre muito subestimado nas pesquisas. É bem plausível que tão vultosa expressão seja uma peculiaridade mineira e até mesmo belo-horizontina, peculiaridade, também possivelmente, resultante da influência de Chico Xavier ${ }^{5}$. Mas resulta claro que o espiritismo deve ser melhor compreendido entre nós, principalmente em sua dimensão oculta, e o espiritismo parece um sujeito oculto. É possível que, para além dos números, ele esteja a prover referências valorativas e normativas cruciais de nossa cultura, mas isso é uma outra história.

Freqüência à reunião espírita

\begin{tabular}{c|c|c}
\hline Categoria & Contagem de respostas & Percentual de respostas \\
\hline Sim & 548 & 18,8 \\
\hline Não & 2361 & 81,1 \\
\hline Total & 2911 & 100.0 \\
\hline
\end{tabular}

Quanto à consulta em astrólogos, cartomantes, mães de santo ou algum tipo de vidente, $15,3 \%$ dos respondentes afirmaram que freqüentam, freqüentaram ou estão dispostos a freqüentar este tipo de “"serviço espiritual”. Nesse caso, vemos que a "magia" tem seu lugar no concerto das religiosidades e não apenas residual. Aqui também, como no caso do espiritismo, talvez devamos ir além dos números e investigar melhor as implicações culturais específicas que a magia pode estar a promover entre nós. 
Freqüência à consultas em astrólogos, cartomantes

\begin{tabular}{c|c|c}
\hline Categoria & Contagem de respostas & Percentual de respostas \\
\hline Sim & 459 & 15,3 \\
\hline Não & 2535 & 84,7 \\
\hline Total & 2994 & 100.0 \\
\hline
\end{tabular}

O conjunto dos dados relativos à freqüência ou disposição para freqüentar mais de um tipo de culto ou ritual mágico-religioso permite aventar outras hipóteses interessantes sobre a natureza da vida religiosa belo-horizontina. Com efeito, somadas as respostas positivas a todos os quesitos, obtém-se uma média de 2,4 "participações" por pessoa. Dito de forma a realçar esse dado e tomando o termo religião no sentido mais amplo possível, como participação institucional, diríamos que cada pessoa tem ou pratica, em média, 2,4 "religiões" em Belo Horizonte. Esse número indica, sobretudo, um intenso trânsito religioso, que entre nós assumiria diversas formas, além da conversão clássica. Percebe-se, sobretudo, uma grande tolerância para com expressões religiosas diversas, reforçando a hipótese referente ao sincretismo e ao "não fundamentalismo". Esses dados indicam também que, contrariamente às teses de "desinstitucionalização" religiosa, as atuais parecem gozar de ampla legitimidade, embora num contexto de competição não exclusivista e pluralista.

\section{Cheios de graça}

A pergunta seguinte do módulo procurou captar elementos que pudessem levar ao dimensionamento do que poderíamos chamar os poderes especificamente mágico-religiosos - os carismas - que as pessoas se auto-atribuem. Evidentemente, esta é uma operacionalização um tanto estranha do conceito de carisma, que significa sociologicamente exatamente o reconhecimento do poder, magicamente fundado, de alguém por outrem. Contudo, tal operacionalização pode ser útil para revelar uma hierarquia especificamente intra-religiosa, referida às posições no campo, principalmente as mais baixas, tais como são percebidas pelos indivíduos e que apenas parcialmente coincidiria com as hierarquias oficiais ou amplamente reconhecidas. Desse modo, buscou-se alguma medida mais específica do elemento mágico na composição da atitude religiosa das pessoas. Foi-lhes perguntado se elas possuíam algum dom e sugerimos a premonição, a mediunidade e a fé.

Os dados indicam que aproximadamente um terço das pessoas da amostra acredita possuir o dom da premonição, um sétimo, da mediunidade e praticamente todas, da fé. Uma interpretação intuitiva desses dados leva-nos a considerálos excepcionalmente altos, denotando, em nossa perspectiva, consoante com nosso sincretismo, um fortíssimo componente mágico em nossa religiosidade, com implicações importantes. Esses poderes confessos, embora não representem os "verdadeiros" poderes do campo religioso, revelam aqueles que os almejam, ou que pelo menos se acham capazes deles. Por outras palavras, haveria por todo 
o campo religioso uma acirrada luta por posições religiosas, aferidas nessa pesquisa em termos de poderes extraordinários auto-atribuídos. Esses poderes, presume-se, difeririam em grau, o que implicaria uma ordem religiosa fundada de alto a baixo na desigualdade e na hierarquia. Aí se revelaria uma importante conotação da forma "eclesial", e não "sectária" de nossas relações religiosas, possivelmente com correspondências em outras esferas da vida social.

Dons que acredita possuir - Premonição

\begin{tabular}{c|c|c|c|c}
\hline & Freqüência & Percentual & Percentual Válido & $\begin{array}{c}\text { Percentual } \\
\text { Acumulado }\end{array}$ \\
\hline S1 & 1 &, 1 & & \\
\hline Sim & 364 & 35,4 & 35,4 & 35,4 \\
\hline Não & 648 & 63,0 & 63,0 & 98,4 \\
\hline NR & 10 &, 9 &, 9 & 99,4 \\
\hline NS & 6 &, 6 & 100,6 & 100,0 \\
\hline Total & 1029 & 100,0 & &
\end{tabular}

Dons que acredita possuir - Mediunidade

\begin{tabular}{c|c|c|c|c}
\hline & Freqüência & Percentual & Percentual Válido & $\begin{array}{c}\text { Percentual } \\
\text { Acumulado }\end{array}$ \\
\hline Sim & 151 & 14,6 & 14,6 & 97,9 \\
\hline Não & 857 & 83,3 & 83,3 & 98,5 \\
\hline NR & 5 &, 5 &, 5 & 100,0 \\
\hline NS & 16 & 1,5 & 1,5 & 100,0 \\
\hline
\end{tabular}

Dons que acredita possuir - Fé

\begin{tabular}{c|c|c|c|c}
\hline & Freqüência & Percentual & Percentual Válido & $\begin{array}{c}\text { Percentual } \\
\text { Acumulado }\end{array}$ \\
\hline Sim & 970 & 94,3 & 94,3 & 94,3 \\
\hline Não & 56 & 5,4 & 5,4 & 99,7 \\
\hline NR & 1 &, 1 &, 1 & 99,8 \\
\hline NS & 2 &, 2 &, 2 & 100,0 \\
\hline Total & 1029 & 100,0 & 100,0 & \\
\hline
\end{tabular}

\section{Quatro grandes grupos religiosos}

Só depois de indagadas sobre suas crenças, suas práticas, seus poderes é que as pessoas foram perquiridas sobre seu pertencimento religioso. A ordem das opções oferecidas é a que aparece na tabela abaixo. As diferenças dos valores obtidos em nossa pesquisa daqueles do Censo e de outras pesquisas por amostra suscitam interessantes questões. 
Religião a que pertence

\begin{tabular}{l|c|c|c}
\hline & Freqüência & Percentual & Percentual Válido \\
\hline Espírita & 47 & 4.6 & 4.6 \\
\hline Evangélico(a) & 235 & 22.9 & 22.9 \\
\hline Católico(a) praticante & 446 & 43.4 & 43.4 \\
\hline Católico(a) não praticante & 210 & 20.4 & 20.4 \\
\hline Da religião dos Orixás & 9 & .9 & .9 \\
Nao tem religláo & 54 & 5.2 & 5.2 \\
\hline Outra & 26 & 2.6 & 2.6 \\
\hline NR & 1 & .1 & .1 \\
\hline Total & 1029 & 100.0 & 100,0 \\
\hline
\end{tabular}

No campo católico incluímos a categoria "não praticante", que resultou em $20,4 \%$ da amostra e seria a terceira maior religião belo-horizontina, atrás dos "praticantes", com 43,4\% da amostra e dos evangélicos, com 22,9\%. Haveria que se entender melhor o significado desse tipo de religiosidade que assim se define: como "católico não praticante", bem como os "sem religião", o quarto maior grupo. Em todo caso, essa seria, talvez, uma configuração mais realista das religiões dominantes no campo religioso que aquelas reveladas pelo Censo e outras pesquisas. Ali, os católicos representariam cerca de $75 \%$ da população e os evangélicos, cerca de $15 \%$. Além disso, os espíritas apareceram com valores significativamente menores que os 4,6\% obtidos em nossa pesquisa. Em síntese, distintamente de uma configuração amplamente dominada pelo catolicismo e coadjuvada pelos evangélicos, tal como é comumente aceita, chegamos a uma configuração onde pelo menos quatro grupos podem reivindicar posições de religiões de massa, "universais".

\section{Religião e estrutura social}

Extrapolando o campo estrito da religião, visando a explorar possíveis conexões com dimensões estruturais da sociedade, o cruzamento abaixo revelou forte associação entre gênero e pertencimento religioso.

Sexo* religião que pertence

\begin{tabular}{l|c|c|c|c|c|c|c}
\hline \multirow{2}{*}{ Sexo } & \multicolumn{6}{|c|}{ Religião que pertence } & \multirow{2}{*}{ Total } \\
\cline { 2 - 7 } & Espírita & Evangélico(a) & $\begin{array}{c}\text { Católico(a) } \\
\text { praticante }\end{array}$ & $\begin{array}{c}\text { Católico(a) } \\
\text { não praticante }\end{array}$ & $\begin{array}{c}\text { Da religião } \\
\text { dos Orixás }\end{array}$ & $\begin{array}{c}\text { Não tem } \\
\text { religião? }\end{array}$ & \\
\hline Homem & 16 & 99 & 204 & 127 & 6 & 37 & 489 \\
& $3.3 \%$ & $20.2 \%$ & $41.7 \%$ & $26.0 \%$ & $1.2 \%$ & $7.6 \%$ & $100.0 \%$ \\
\hline Mulher & 31 & 136 & 243 & 83 & 4 & 17 & 514 \\
& $6.0 \%$ & $26.5 \%$ & $47.3 \%$ & $16.1 \%$ & $.8 \%$ & $3.3 \%$ & $100.0 \%$ \\
\hline Total & 47 & 235 & 447 & 210 & 10 & 54 & 1003 \\
& $4.7 \%$ & $23.4 \%$ & $44.6 \%$ & $20.9 \%$ & $1.0 \%$ & $5.4 \%$ & $100.0 \%$ \\
\hline
\end{tabular}




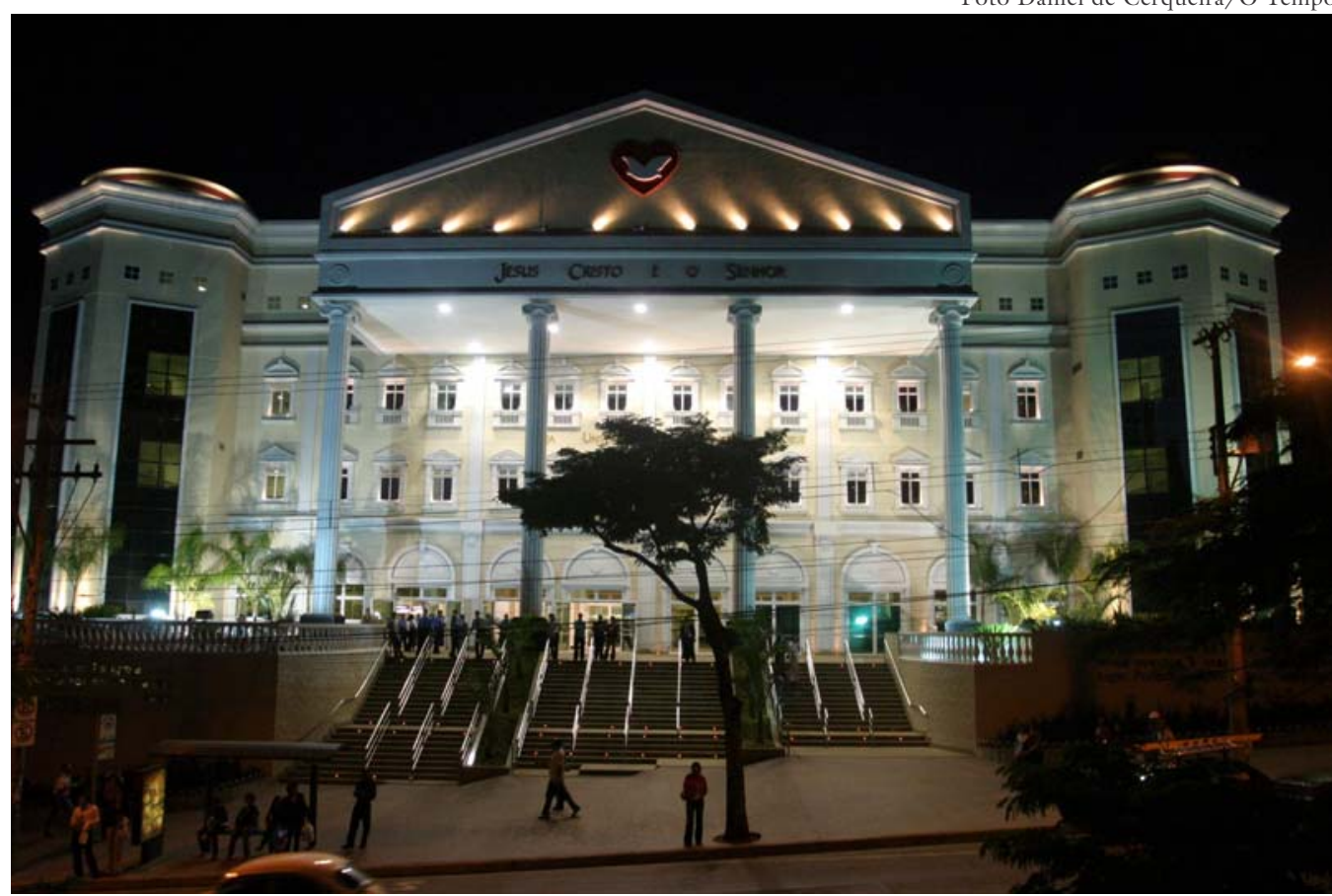

Templo da Igreja Universal do Reino de Deus na cidade de Belo Hozinte, MG.

Vê-se nessa tabela que, enquanto as mulheres predominam entre os espíritas, evangélicos e católicos praticantes, os homens predominam entre os católicos não praticantes e os sem religião.

Também encontramos forte associação entre renda e pertencimento religioso. Espíritas, católicos não praticantes e sem religião têm renda familiar significativamente maior que os católicos praticantes e maior ainda que os evangélicos.

Renda familiar resumida* Religião que pertence

\begin{tabular}{|c|c|c|c|c|c|c|c|c|}
\hline \multirow[b]{3}{*}{$\begin{array}{l}\text { renda } \\
\text { familiar } \\
\text { resumida }\end{array}$} & & & \multicolumn{5}{|c|}{ R4 - Religião que pertence } & \multirow[b]{2}{*}{ Total } \\
\hline & & & Espírita & Evangélico(a) & $\begin{array}{c}\text { Católico(a) } \\
\text { praticante }\end{array}$ & \begin{tabular}{|c|} 
Católico(a) \\
não praticante
\end{tabular} & $\begin{array}{l}\text { Não tem } \\
\text { religião? }\end{array}$ & \\
\hline & até 1 salário mínimo & $\begin{array}{l}\text { Número } \\
\text { Número Esperado } \\
\% \text { Com renda } \\
\text { Familiar resumida }\end{array}$ & $\begin{array}{c}0 \\
2,1 \\
0 \%\end{array}$ & $\begin{array}{c}21 \\
15,9 \\
\\
33,3 \%\end{array}$ & $\begin{array}{c}31 \\
28,3 \\
49,2 \%\end{array}$ & $\begin{array}{c}10 \\
13,2 \\
\\
15,9 \%\end{array}$ & $\begin{array}{c}1 \\
3,5 \\
1,6 \%\end{array}$ & $\begin{array}{c}63 \\
63,0 \\
100,0 \%\end{array}$ \\
\hline & $\begin{array}{l}\text { mais de } 1 \text { até } 3 \\
\text { salários mínimos }\end{array}$ & $\begin{array}{l}\text { Número } \\
\text { Número Esperado } \\
\% \text { Com renda } \\
\text { Familiar resumida }\end{array}$ & $\begin{array}{c}8 \\
10,0 \\
2,7 \%\end{array}$ & $\begin{array}{c}93 \\
75,4 \\
31,2 \%\end{array}$ & $\begin{array}{c}120 \\
133,8 \\
40,3 \%\end{array}$ & $\begin{array}{c}59 \\
62,3 \\
19,8 \%\end{array}$ & $\begin{array}{c}18 \\
16,5 \\
6,0 \%\end{array}$ & $\begin{array}{c}298 \\
298,0 \\
100,0 \%\end{array}$ \\
\hline & $\begin{array}{l}\text { mais de } 3 \text { até } 5 \\
\text { salários mínimos }\end{array}$ & $\begin{array}{l}\text { Número } \\
\text { Número Esperado } \\
\% \text { Com renda } \\
\text { Familiar resumida }\end{array}$ & $\begin{array}{c}9 \\
6,5 \\
4,6 \%\end{array}$ & $\begin{array}{c}45 \\
49,3 \\
\\
23,1 \%\end{array}$ & $\begin{array}{c}91 \\
87,6 \\
46,7 \%\end{array}$ & $\begin{array}{c}37 \\
40,8 \\
\\
19,0 \%\end{array}$ & $\begin{array}{c}13 \\
10,8 \\
6,7 \%\end{array}$ & $\begin{array}{c}195 \\
195,0 \\
100,0 \%\end{array}$ \\
\hline & $\begin{array}{l}\text { mais de } 5 \\
\text { salários mínimos }\end{array}$ & $\begin{array}{l}\text { Número } \\
\text { Número Esperado } \\
\% \text { Com renda } \\
\text { Familiar resumida }\end{array}$ & $\begin{array}{c}9 \\
7,3 \\
4,1 \%\end{array}$ & $\begin{array}{c}37 \\
55,4 \\
16,9 \%\end{array}$ & $\begin{array}{r}106 \\
98,3 \\
48,4 \%\end{array}$ & $\begin{array}{c}56 \\
45,8 \\
25,6 \%\end{array}$ & $\begin{array}{c}11 \\
12,2 \\
5,0 \%\end{array}$ & $\begin{array}{c}219 \\
219,0 \\
100,0 \%\end{array}$ \\
\hline Total & & $\begin{array}{l}\text { Número } \\
\text { Número Esperado } \\
\% \text { Com renda } \\
\text { Familiar resumida }\end{array}$ & $\begin{array}{c}26 \\
26,0 \\
3,4 \%\end{array}$ & $\begin{array}{c}196 \\
196,0 \\
25,3 \%\end{array}$ & $\begin{array}{c}348 \\
348,0 \\
44,9 \%\end{array}$ & $\begin{array}{c}162 \\
162,0 \\
20,9 \%\end{array}$ & $\begin{array}{c}43 \\
43,0 \\
5,5 \%\end{array}$ & $\begin{array}{c}775 \\
775,0 \\
100,0 \%\end{array}$ \\
\hline
\end{tabular}

Também a variável raça se associa com pertencimento religioso, revelando uma concentração de brancos entre os espíritas e os católicos não praticantes e 
uma concentração de não brancos entre os evangélicos. Já entre os católicos praticantes, essa associação é menor e inexiste entre os sem religião.

\begin{tabular}{|c|c|c|c|c|c|c|c|c|}
\hline \multirow{4}{*}{$\begin{array}{l}\text { raça indicadora } \\
(\text { branco }=1)\end{array}$} & & & \multicolumn{5}{|c|}{ R4 - Religião que pertence } & \multirow{2}{*}{ Total } \\
\hline & & & Espírita & Evangélico(a) & $\begin{array}{c}\text { Católico(a) } \\
\text { praticante }\end{array}$ & $\begin{array}{c}\text { Católico(a) } \\
\text { não praticante }\end{array}$ & $\begin{array}{l}\text { Não tem } \\
\text { religião? }\end{array}$ & \\
\hline & $\begin{array}{l}\text { não branco } \\
\text { (negro) }\end{array}$ & $\begin{array}{l}\text { Número } \\
\text { Número Esperado } \\
\% \text { com raça } \\
\text { Indicadora }(\text { branco }=1 \text { ) }\end{array}$ & $\begin{array}{c}28 \\
32,9 \\
4,2 \%\end{array}$ & $\begin{array}{c}181 \\
160,4 \\
\\
26,9 \%\end{array}$ & $\begin{array}{c}294 \\
298,1 \\
43,7 \%\end{array}$ & $\begin{array}{c}134 \\
145,3 \\
19,9 \%\end{array}$ & $\begin{array}{c}36 \\
36,3 \\
5,3 \%\end{array}$ & $\begin{array}{c}673 \\
673,0 \\
100,0 \%\end{array}$ \\
\hline & branco & $\begin{array}{l}\text { Número } \\
\text { Número Esperado } \\
\% \text { com raça } \\
\text { Indicadora (branco=1) }\end{array}$ & $\begin{array}{c}20 \\
15,1 \\
6,5 \%\end{array}$ & $\begin{array}{c}53 \\
73,6 \\
\\
17,2 \%\end{array}$ & $\begin{array}{c}141 \\
136,9 \\
45,6 \%\end{array}$ & $\begin{array}{c}78 \\
66,7 \\
25,2 \%\end{array}$ & $\begin{array}{c}17 \\
16,7 \\
5,5 \%\end{array}$ & $\begin{array}{c}309 \\
309,0 \\
100,0 \%\end{array}$ \\
\hline Total & & $\begin{array}{l}\text { Número } \\
\text { Número Esperado } \\
\% \text { com raça } \\
\text { Indicadora }(\text { branco }=1 \text { ) }\end{array}$ & $\begin{array}{c}48 \\
48,0 \\
4,9 \%\end{array}$ & $\begin{array}{c}234 \\
234,0 \\
23,8 \%\end{array}$ & $\begin{array}{c}435 \\
435,0 \\
\\
44,3 \%\end{array}$ & $\begin{array}{c}212 \\
212,0 \\
21,6 \%\end{array}$ & $\begin{array}{c}53 \\
53,0 \\
5,4 \%\end{array}$ & $\begin{array}{c}982 \\
982,0 \\
100,0 \%\end{array}$ \\
\hline
\end{tabular}

O que significam esses dados é algo que apenas cogitamos intuitivamente. Não são nada óbvios os nexos que aproximam mulheres, negros e pobres das religiões evangélicas, nem os que aproximam homens, brancos e ricos do catolicismo não praticante. De todo modo, as respostas devem ser buscadas nas religiões,

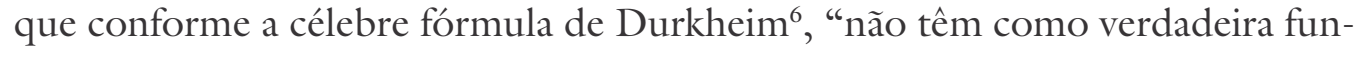
ção fazer-nos pensar, enriquecer nosso conhecimento, acrescentar às representações que devemos à ciência representações de uma outra origem e de um outro caráter, mas a de fazer-nos agir, auxiliar-nos a viver". Entender se e como cada um dos quatro grandes grupos religiosos, ou quatro estilos dominantes de religiosidade, realiza essa função é um desafio que os dados estão a fazer-nos, pois das respostas depende uma melhor compreensão da atuação de mecanismos estruturais de nossa sociedade.

\section{Considerações finais}

Antes de tudo, cabe-nos reconhecer a ligeireza com que foram tratados os dados da pesquisa em foco. Justificamo-nos, sobretudo, pelo desejo de partilhar esses achados e algumas hipóteses interpretativas, antes mesmo de poder realizar análises mais acuradas. Há também uma consideração a fazer sobre as possibilidades de generalização e de comparação desses dados. Sabemos pelo Censo e por outras pesquisas ${ }^{7}$ que há peculiaridades regionais relativamente à configuração do campo religioso. Belo Horizonte é reconhecidamente tradicionalista, se com isso queremos dizer que há ali uma proporção maior de católicos e menor de seguidores de outras religiões e dos sem religião. Em outras capitais e grandes centros percebem-se proporções maiores exatamente dessas demais categorias, como, por exemplo, de evangélicos no Rio de Janeiro. Mesmo assim, pensamos que os dados de nossa pesquisa refletem muito da realidade social das religiões, vale dizer, dos estilos de religiosidade, nos grandes centros urbanos brasileiros.

Há também que se esclarecer o (ab)uso de aspas no texto. Muitos termos, nesse campo, são objetos de disputa e/ou controvérsia, não apenas semântica, 
mas também política. Evangélicos, fundamentalismo e magia, por exemplo, incorrem naqueles casos. Com as aspas, quisemos neutralizar axiologicamente os termos usados, chamando a atenção para seu significado operacional, no contexto da pesquisa. Assim, magia, entre aspas, está significando no texto esse cosmo social adjacente às religiões, composto de atores, ações e representações específicas, socialmente reconhecidas como mágicos. Além dessa magia, entre aspas, haveria toda a magia presente nas religiões e as magias metafóricas, que ficam fora do termo. No caso do fundamentalismo, quisemos permanecer dentro da tradição de identificá-lo com a ortodoxia sacerdotal e, por evangélicos, quisemos englobar uma grande variedade de igrejas, até o limite daquelas que designaríamos por "outras religiões".

Há também que se chamar atenção para o desenho do módulo de religião de nossa pesquisa. Como se viu, informados pela pesquisa qualitativa disponível, presumimos que certas dimensões da experiência religiosa são particularmente dificeis de aferir e que as perguntas convencionais nesse campo tendem a produzir respostas convencionais, mais do que indicações da própria experiência. Até mesmo a ordem das questões e dos itens apresentados aos entrevistados pode ter muito mais importância do que parece. Tentamos uma abordagem que poderíamos chamar "inquisitiva”, para ressaltar a utilização de recursos táticos na formulação das perguntas, que levassem as pessoas a "revelar" seus vínculos e idéias religiosas.

Se nos é permitido terminar explorando uma metáfora, diríamos que a religião pode ser considerada uma espécie de código, que permite o desvendamento de dimensões cruciais da cultura e, portanto, do destino dos povos. Mas só uma perfeita decodificação da religião possibilita a análise cultural promissora. Decodificações “defeituosas” produzem visões necessariamente enviesadas. Aqui, não pretendemos ter decifrado perfeitamente o código religioso, mas tão-somente ter mostrado que as chaves habitualmente usadas para isso podem não ser as melhores possíveis.

\section{Notas}

1 Em referências muito tópicas, a larga tradição da sociologia da religião no Brasil remonta a Fernando de Azevedo (1943), Gilberto Freyre (1959), Candido Procópio Camargo (1973), se desdobrando nas duas oltimas décadas em um grande número de autores e de especializações, donde destacamos as abordagens abrangentes de Flávio Pierucci e Reginaldo Prandi (1996). Mais diretamente, a idéia da pergunta sobre crenças foi desenvolvida a partir de uma formulação de Leandro Piquet Carneiro e Luís Eduardo Soares citada por C. R. Brandão, 1994.

2 Ver P. Sanchis, 1994, 1995 e 1999.

3 Ver Weber, 1984. 
4 Ver A. Cardoso; L. Perez e L. Oliveira, 2001 e A. Cardoso; C. Leite e M. Nogueira, 2002.

5 Ver Cardoso, 1999.

6 Ver Durkheim, 1978.

7 Ver referência da nota 4.

Bibliografia

AZEVEDO, Fernando. A cultura brasileira. São Paulo, Melhoramentos, 1943.

BRANDÃO, Carlos Rodrigues. "A crise das instituições tradicionais produtoras de sentido”, em MOREIRA, Alberto e ZICMAN, Renée (orgs.). Misticismo e novas religiões. Petrópolis, Vozes, 1994, p 40.

CAMARGO, Candido Procópio Ferreira de. Católicos, protestantes, espiritas. Petrópolis, Vozes, 1973.

CARDOSO, Alexandre; LEITE, Cláudio e NOGUEIRA, Maria de Fátima. "Pesquisa quantitativa no campo religioso; reflexões ulteriores sobre a experiência de um grupo acadêmico de estudos da religião em duas pesquisas quantitativas". Rever; revista de estudos da religião. PUC-SP (www.pucsp.br/rever), 2002.

CARDOSO, Alexandre; PEREZ, Lea e OLIVEIRA, Luciana. "Quem mora ao lado? O pecado ou a virtude? Um estudo comparativo sobre a participação religiosa e política entre estudantes de Ciências Sociais e de Comunicação da FAFICH-UFMG". Debates do NER-UFRGS, ano 2, n. 2, Porto Alegre, 2001, pp. 65-102.

CARDOSO, Alexandre. Os alquimistas já chegaram: uma interpretação sociológica das práticas mágicas em Belo Horizonte. Tese de Doutorado, FFCH-USP, 1999.

Censo 2001, IBGE.

DURKHEIM, Émile. As formas elementares da vida religiosa. São Paulo, Abril Cultural, 1978, p. 220 (Col. Os Pensadores).

ELIADE, Mircea. Ocultismo, bruxaria e correntes culturais: ensaios em religiões comparadas. Belo Horizonte, Interlivros, 1979.

FREYRE, Gilberto. Ordem e progresso. $2^{\circ}$ tomo, Rio de Janeiro, Livraria José Olímpio, 1959.

MENDONÇA, Antônio Gouvêa. "Religiosidade no Brasil: imaginário, pós-modernidade e formas de expressão". Em Estudos da religião; estratégias religiosas na sociedade brasileira. São Paulo, n. 15, Umesp, 1998.

NöTH, Winfried. "Semiótica da magia”, Revista USP, dossiê magia, 31, São Paulo, 1989.

PIERUCCI, Antônio Flávio e PRANDI, Reginaldo. A realidade social das religiões no Brasil. São Paulo, Hucitec, 1996.

SANCHIS, Pierre. "A dança do sincretismo", Comunicações do ISER, n. 45, Rio de Janeiro, Publicações do Iser, 1994. 
. "As tramas sincréticas da história”. Revista Brasileira de Ciências Sociais, São Paulo, Anpocs, n. 28, 1995, pp. 123-138.

"A religião dos brasileiros". Teoria e Sociedade. Belo Horizonte, UFMG, n. 4, 1999, pp. 55-72.

THOMAS, Keith. Religion and the Decline of Magic. New York, Penguin, 1985.

WALLS, Roy. "New religions and the potential of word re-enchantment: religion as way of life, preference and commodity". Secularization and Religion: the persisting tension. Lausanne e Tubingen. Conference Internationale de Sociologie des Religions, 1987.

WEBER, Max. Economia y Sociedad. $7^{a}$ reimp., México, Fondo de Cultura Económica, 1984 , pp. 328 e ss.

RESUMO - O TRABALHO faz uma exploração preliminar dos dados sobre religião de um survey da região metropolitana de Belo Horizonte, concluído em 2002. Apresenta e comenta algumas freqüências simples referentes a crenças, envolvimento e poderes religiosos, bem como alguns cruzamentos de pertencimento religioso com variáveis estruturais.

ABSTRACT - THIS ESSAY is a preliminary investigation of the religious data from a survey carried out in Belo Horizonte's metropolitan area and concluded in 2002. We present and comment upon some simple frequencies pertaining to beliefs, involvement and religious powers, as well as the blending between religious establishments and structural variables.

Alexandre Cardoso é professor adjunto do Departamento de Sociologia e Antropologia da Universidade Federal de Minas Gerais (UFMG). É doutor em Sociologia pela FFLCHUSP e coordenador do Centro de Estudos da Religião Pierre Sanchis (Cersp), da FAFICHUFMG.

Texto recebido e aceito para publicação em 5 de outubro de 2004 . 